\title{
Envisioning Futures of Design Education: An Exploratory Workshop with Design Educators
}

SAPNA SINGH, ${ }^{1}$ NICOLE LOTZ, ${ }^{2}$ AND ELIZABETH B.-N. SANDERS ${ }^{3}$

1. The Ohio State University, Columbus, Ohio, USA

2. The Open University, Milton Keynes, UK

3. The Ohio State University, Columbus, Ohio, USA and MakeTools, USA

SUGGESTED CITATION: Singh, S., Lotz, N. \& Sanders, E.B.-N. “Envisioning Futures of Design

Education.” Dialectic, 2.1 (2018): pgs. 19-46. DOI: http://dx.doi.org/10.3998/dialectic.14932326.0002.103

\section{Abstract}

The demand for innovation in the creative economy has seen the adoption and adaptation of design thinking and design methods into domains outside design, such as business management, education, healthcare, and engineering. Design thinking and methodologies are now considered useful for identifying, framing and solving complex, often wicked social, technological, economic and public policy problems. As the practice of design undergoes change, design education is also expected to adjust to prepare future designers to have dramatically different demands made upon their general abilities and bases of knowledge than have design career paths from years past. Future designers will have to develop skills and be able to construct and utilize knowledge that allows them to make meaningful contributions to collaborative efforts involving experts from disciplines outside design. Exactly how future designers should be prepared to do this has sparked a good deal of conjecture and debate in the professional and academic design communities.

This report proposes that the process of creating future scenarios that more broadly explore and expand the role, or roles, for design and designers in the world's increasingly interwoven and interdependent societies can help uncover core needs and envision framework(s) for design education. This approach informed the creation of a workshop ${ }^{\mathbf{1}}$ held at the Design Research Society conference in Brighton, UK in June of 2016, where six design educators shared four future scenarios that served as catalysts for conversations about the future of design education. Each scenario presented a specific future design education context. One scenario described the progression of design education as a core component of K-12 curricula; another scenario situated design at the core of a network of globally-linked local Universities; the third scenario highlighted the expanding role of designers over time; and the final scenario described a distance design education context that made learning relevant and "close" to an individual learner's areas of interest. Forty participants in teams of up to six were asked to collaboratively visualize a possible future vision of design 
education based on one of these four scenarios and supported by a toolkit consisting of a set of trigger cards (with images and text), along with markers, glue and flipcharts. The collaborative visions $^{2}$ that were jointly created as posters using the toolkit and then presented by the teams to all the workshop participants and facilitators are offered here as a case study. Although inspired by different scenarios, their collectively envisioned futures of what design education should facilitate displayed some key similarities. Some of those were:

- Future design education curricula will focus on developing collaborative approaches within which faculty and students are co-learners;

- These curricula will bring together ways of learning and knowing that stem from multiple disciplines; and

- Learning in and about the natural environment will be a key goal (the specifics of how that would be accomplished were not elaborated upon.)

In addition, the need for transdisciplinarity ${ }^{3}$ was expressed across the collaborative visions created by each of the teams, but the manner that participants chose to express their ideas about this varied. Some envisioned that design would evolve by drawing on other disciplinary knowledge, and others envisioned that design would gradually integrate with other disciplines.

1 This workshop was attended by $40+$ participants who formed six working groups.

2 Collaborative vision is defined here as a collectively developed and shared imaginative idea of the future that can then be used to guide a program of actions to realize the vision. The definition builds on what van der Helm defined as community vision (for more information about this, please reference p. 98 of Ruud van der Helm's article "The Vision Phenomenon: Towards a Theoretical
Underpinning of Visions of the Future and the Process of Envisioning" in Volume 41, Issue 2 of Futures Methodologies.)

3 Transdisciplinarity refers to an approach that crosses and connects many disciplinary boundaries. It is especially relevant to identifying, framing and resolving complex and wicked problems that transcend the boundaries between two or more disciplines. 


\title{
Envisioning Futures of Design Education:
}

\author{
An Exploratory Workshop with Design Educators
}

SAPNA SINGH, NICOLE LOTZ, \& ELIZABETH B.-N. SANDERS

\section{Introduction}

Over the course of roughly the past 40 years, design practice and education across much of the world has been undergoing intensive changes to address shifts that have occurred as manufacturing economies have given way to service economies. Design processes have evolved from yielding mostly physical to digital products, and from a culture that celebrated "star designers" to cultures (plural) that celebrate co-designing with diverse design teams. ${ }^{4,5}$ Design educators are faced with the challenge of keeping up with this rapid pace of change, as well as having to anticipate the kinds of future demands that design education experiences will have to meet. A crucial set of questions stem from this: what do design educators and administrators of design education need to know about where design education is heading in the next five to fifteen years and why? How can they participate in shaping the knowledge and understand-

4

Broadbent, J. \& Cross, N. "Design Education in the Information Age." Journal of Engineering Design, 14.4 (2003): pgs. 439-446.

\section{5}

Buchanan, R. "The Problem of Character in Design Education: Liberal Arts and Professional Specialization." International Journal of Technology and Design Education, 11.1 (2001): pgs. $13-26$. ing that will guide its evolution to affect positive change?

This paper argues that it is important to gain a long-term and visionary understanding of social, technological, economic, environmental and political factors impacting design practice and education to develop curricula for future design programs. Curricula for design courses are often developed in response to external events: national or institutional structural changes, growth opportunities in particular industry sectors, or advances in knowledge in a particular discipline. Considering the dynamic complexities of their operational contexts, educators and educational administrators have very little opportunity 
to develop a long-term vision for the design discipline. Furthermore, techniques and tools that have been shown to guide effective and practical curriculum design in higher education are scarce. ${ }^{6} \mathrm{~A}$ long-term view of the possible futures for design education would allow design educators and their administrators to be more agile planners and more flexible facilitators. It would give them a better understanding of where design as a discipline might be headed, help them to identify curricular needs for those future(s), and facilitate their role in leading and shaping curricular change. This conceptual approach was the foundation for planning and facilitating a visioning workshop on the "Future of Design Education" that was conducted at the Design Research Society (DRS2016) conference in Brighton, UK. The goal of the workshop was to explore possible futures for design education based within the context of different future scenarios which presented factors, conditions and situations that could influence design education. ${ }^{7}$

This paper presents the observations distilled from this visioning workshop, and its outcomes are articulated in the form of a case-study report. It begins with a brief description of the visioning method that was facilitated by the workshop leaders to help workshop participants engage in the process of generating ideas that could guide or affect curricular change in design education. The report continues by describing the activities that transpired within the workshop itself, the description of the possible future scenarios impacting design education and culminates with a discussion of the visualizations representing the visions of the workshop participants. In this context, visions are descriptions of some of the issues, examined singly or in related groups, that design curricula of the future will have to effectively address. The report concludes with a critical examination of these visions, and highlights key observa-

Broadbent, J. \& Cross, N. "Design Education in the Information Age." Journal of Engineering Design, 14.4 (2003): pgs. 439-446. 7

Singh, S., Irwin, T., Sanders, E., Stappers, P. J., Lotz, N., \& Bohemia, E. “The Future of Design Education." Workshop facilitated at the Design Research Society Conference, Brighton, UK, June 2016. Online. Available at: https:// drs2016. squarespace. com/564/?rq=future (Accessed January, 19, 2017). tions, similarities and variations.

\section{About the DRS Conference and Visioning Workshop}

The DRS 2016 Conference, held in Brighton, UK in June 2016, was attended by over 200 members of the international design education and research community. The presence and willing participation of such a large group of people who are engaged and invested in trying to effectively facilitate design education made this event conducive to fostering several discussions about the future of design education, including those that transpired within our visioning workshop. This 90-minute workshop was attended by about 40 conference participants. 


\section{8}

Van der Helm, R. "The vision

phenomenon: Towards a theoretical underpinning of visions of the future and the process of envisioning." Futures Methodologies, 41.2 (2009): pgs. 96-104. 9

Sanders, E. B.-N. and Stappers,

P. J. Convivial Toolbox: Generative Research for the Front End of Design. Amsterdam, The Netherlands: BIS Publishers, 2012.
A discussion about the future, or particular aspects of it, required the use of a methodology that offered a framework and stimuli that could trigger constructive discussion. ${ }^{8}$ The workshop facilitators chose the format of a participatory design activity using a generative design toolkit ${ }^{9}$ to provide participants with the means to collaboratively visualize their ideas about what specific aspects of the future of design education might look like. This format facilitated gathering viewpoints from a large group in the limited time of 90 minutes.

\section{A Description of the Workshop Toolkit}

The toolkit developed for the workshop included a set of trigger cards (some depicted images and others contained text; see Figure 1 for examples), along with large paper, markers and glue. The cards were sorted into five categories titled People, Places, Roles, Skills and Statements. These five categories were identified by the workshop facilitators as some of the key components to visualizing any future visions for design education. People and Places cards contained images; People cards depicted images of people — mostly individuals — and some others depicted groups. Places cards depicted images of different places - some indoors and some outdoors. Roles, Skills and Statement cards contained text. Roles and Skills cards contained one or two words (e.g., "Learner," "Making Sense"), supported by a brief description elaborating upon that "role" or "skill". The Statements cards contained short statements, such as, "Design can lead change." Content on the cards could be interpreted in many different ways, including some associated with education and/or design. An inclusive trigger set was created to ensure that diverse options for instigating ideas and thinking were presented in the images or the text, and that there was no single dominating theme that pervaded the subject matter inherent in these. The images of people depicted in the People cards represented diverse age groups, ethnicity, and genders; the visuals depicted in the Places cards represented diverse settings such as indoor spaces, outdoor places and abstract visualizations of environments. Additionally, the toolkit included Wild Cards, which were blank cards. Participants could use them to add words and sketches of their own choosing. Overall, the complete set of trigger cards contained content that was quite broadly constituted, yet it also connected to the main ideas that would be presented by the individuals who acted as catalysts/facilitators in each of the four future scenarios. The participants had the option to use all, some or none of the images and text from the toolkit to build a visual collage on a large sheet 
of paper that represented their ideas about the future of design education in the context of one of the presented future scenarios.

\section{Workshop Participants}

The $4 \mathrm{O}+$ people who participated in the workshop included design educators and students from academic institutions located in many different countries, including the Netherlands, Germany, Denmark, Sweden, Switzerland, the United Kingdom, Hong Kong, Australia, and the United States.

\section{Workshop Facilitators}

The six workshop facilitators were design educators from five different university-level, educational institutions who each possessed varying levels of design education experience and expertise. Three of the facilitators are the co-authors of this report. Sapna Singh is a design researcher, strategist and Lecturer at The Ohio State University in the Us; Liz Sanders is a Design Research consultant and an Associate Professor of Design at The Ohio State University; Terry Irwin is the Head of the School of Design at Carnegie Mellon University in the Us; Pieter Jan Stappers is a faculty member of Industrial Design Engineering at Delft University of Technology in The Netherlands; Nicole Lotz is a Lecturer at the Open University in the UK; Erik Bohemia is the Program Director in the Institute for Design Innovation at Loughborough University in the UK.

\section{Workshop Outline}

The 90-minute workshop was divided into the following three parts:

1. Presentation of future scenarios: The workshop began with a presentation of four future scenarios by the facilitators. The five-minute presentation that introduced each scenario concluded with one or more questions for participants to consider regarding the overarching concept of visioning the future of design education.

2. Participatory design activity: The workshop participants organized themselves into groups of five to seven members. All of those sitting at a given table typically formed a group. Each group chose to discuss one of the future scenarios and visualize some aspects of what the future of design education might be like in the context of that scenario. The groups discussed the scenario, browsed through the toolkit, selected cards that could communicate their ideas 


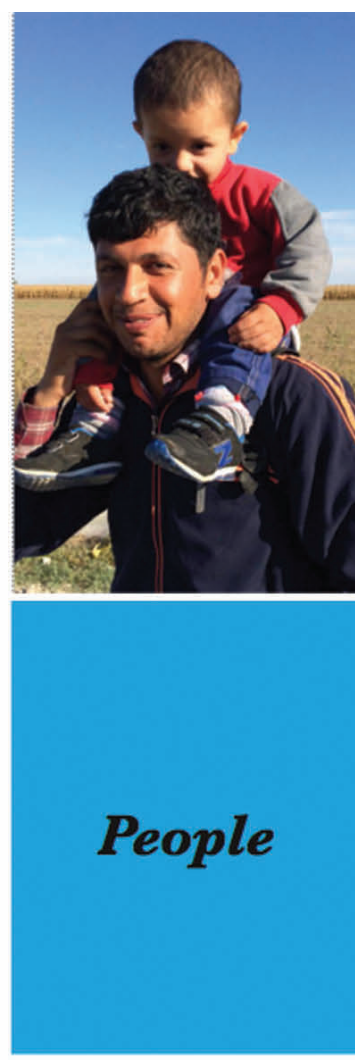

DR52016
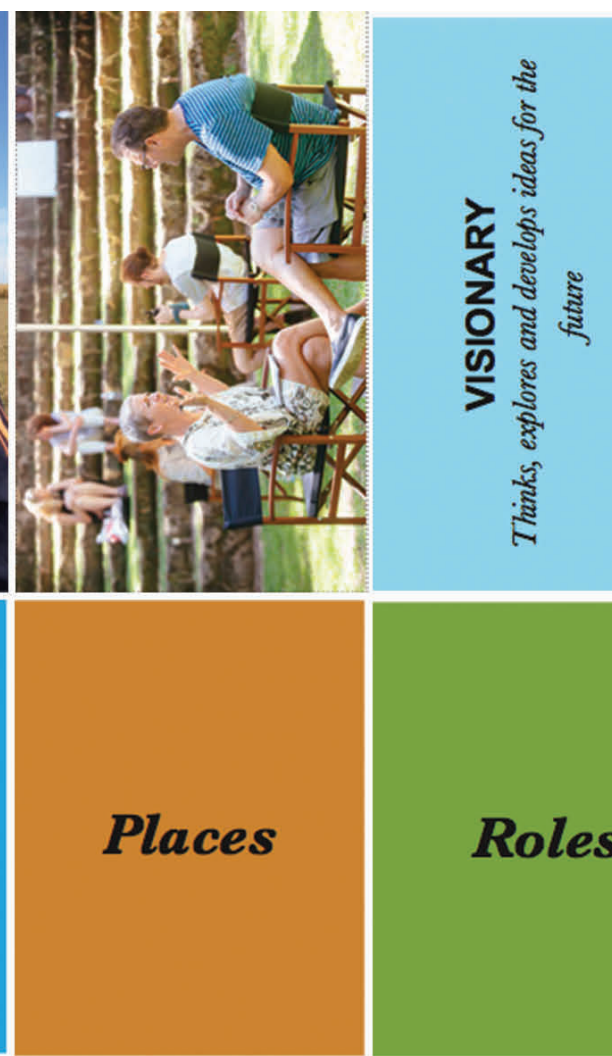

DR52016

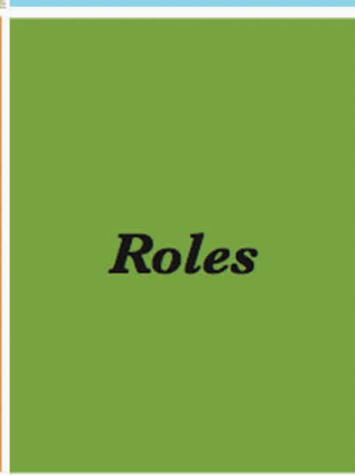

DR52016
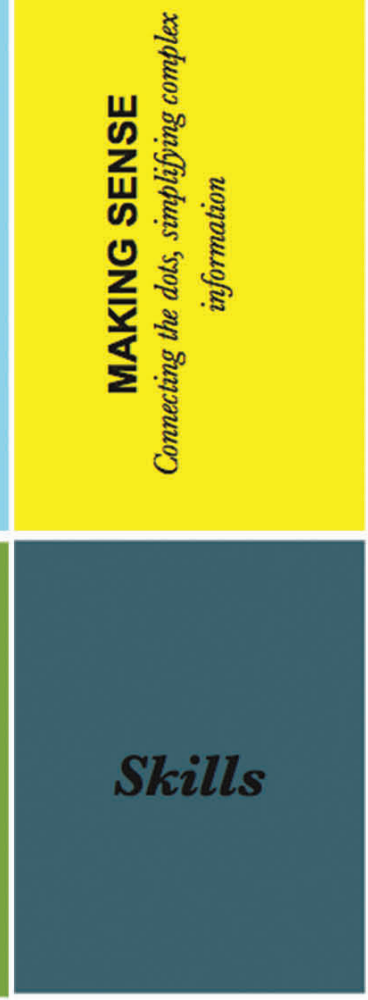

DF52016

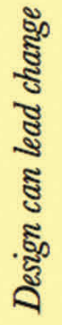

Statements

DR52016

FIGURE 1: An example of trigger cards from the toolkit representing each of the five categories: People, Places, Roles, Skills and Statements. The cards were doublesided with the category names printed on one side and with an image or text printed on the other.

about how and why specific aspects regarding the future of design education might evolve or need to be addressed, and then used the cards to create a visual collage on a large (roughly 36 " x 48 ") sheet of paper. They were also encouraged to add drawings and words of their own choosing to the collage.

3. Presentation of Visions: The workshop concluded with each group presenting their visions for the future of design education - as articulated in their collages - that highlighted the particular array of possibilities, concerns and contextual factors and issues that they felt could or should affect the future of design education. All of the presentations were audio and video-recorded so that the critical dialogues that occurred in and around them could be referenced to provide information and insights to future researchers. 


\section{Four Future Scenarios for Design Education}

The four future scenarios presented by each of the facilitators or facilitation teams offered at least one provocative concept for addressing various aspects of the future of design education. Each facilitator or facilitation team articulated their distinct approaches and viewpoints that catalysed critical conversations across the group of workshop participants, and, eventually within each of the groups that were formed after the scenarios were presented. Each of the four future scenarios that were presented during our workshop are synopsized below:

\section{Scenario \#1: DRAW (Designing, Reading, Arithmetic and Writing)}

\section{Authored and presented by Liz Sanders and Sapna Singh}

The DRAW (Designing, Reading, Arithmetic and Writing) scenario described a future where designing forms the core of a $\mathrm{K}-12$ curriculum together with reading, arithmetic and writing (Figure 2). (K-12 is a term that, in many parts of the us and Canada, refers to primary/elementary, middle and high school education for children aged 5 to 18 years.) This curriculum has three stages:

a. Foundation in Grades K-3: Students collaborate with their peers and family members to understand and develop concrete design knowledge, such as the process of developing a concept or idea and giving form to it. Students also develop foundational skills in empathy and collaboration. Teachers, designers and curriculum developers collaborate to develop toolkits for use in this effort. Children learn about designing through fun, hands-on experiences. They have classes, and workshops in making, repairing, reusing, and repurposing.

b. Exploration in Grades 4-7: Students collaborate with local community members, including families in the neighborhood, businesses, and social and government organizations to tackle and design solutions that meet local community-based needs. The curriculum is project-based, and would bring together knowledge from multiple subject areas relevant to the context that surrounds a given project. Students learn about co-designing and develop toolkits to use in collaborative activities. Hacking (i.e., taking things apart to use the parts to make new things or facilitate better ways of doing things) is introduced in Grade 6. 


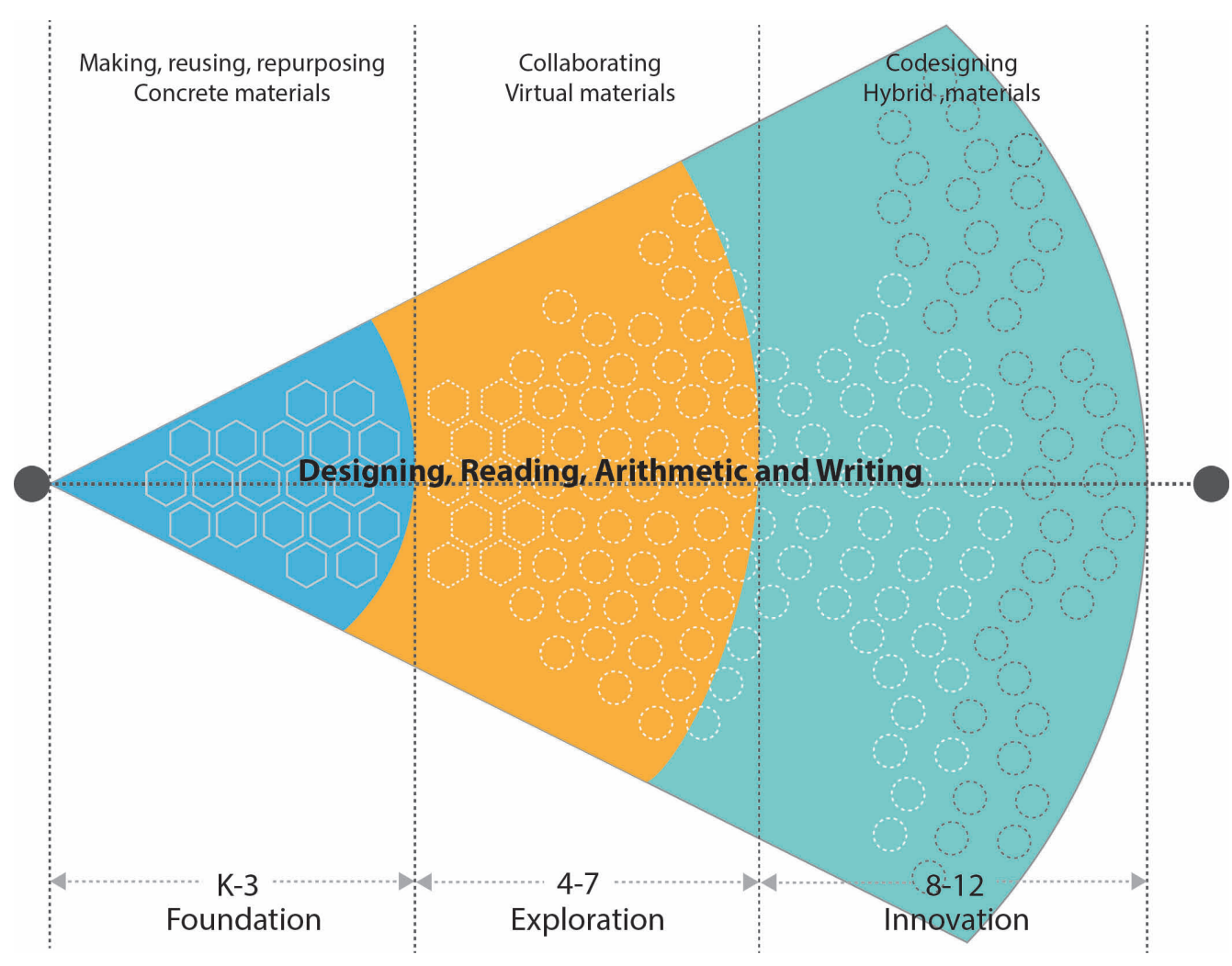

FIGURE 2: Graphic representation of the DRAW (Designing, Reading, Arithmetic and Writing) scenario for primary/elementary (grades K-3; five- to eight-year-old children), middle (grades 4-7; nine- to twelve-year-old children) and high school (grades 8-12; thirteen- to eighteen-year-old children) education.

c. Innovation in Grades 8-12: Students collaborate with social and public organizations to take on real world projects. They explore co-designing with community members across their region, their nation and internationally. Students develop their own co-design toolkits from hybrid (i.e., physical and digital) materials. They learn to effectively engage in the iterative processes of design by practicing it.

In this scenario, meaningful, sustained collaboration among teachers, families and the local community plays a significant role. In the DRAW scenario, the primary goal of $\mathrm{K}-12$ education is to develop smart citizens who will be prepared to be agents of positive change. This scenario will require changes to be made in current assessment standards to place greater emphasis on multicultural, social and humanistic levels of achievement. The primary question was: When 
designing forms the core of K-12 curricula, together with reading, writing and arithmetic, how will higher education in Design change?

\section{Scenario \#2: The Cosmopolitan Localist}

\section{Authored and presented by Terry Irwin}

The Cosmopolitan Localist scenario offered a framework for interdisciplinary education. This scenario is premised on the idea that, by 2030, a global network of Cosmopolitan Localist (CL) Universities would arise in which design will have evolved to be a core discipline on every campus (Figure 3). These universities will serve local and regional populations, and will be linked in their global exchange of knowledge and technology. In this new structure, academic disciplines will offer specialized learning and expertise that is embodied and applied in transdisciplinary collaboration that addresses place-based problems. Placebased problems are problems that are very specific to a location and require designing solutions that address its unique context. Faculty and students will 'toggle' between their home discipline and projects that have been undertaken within transdisciplinary labs to work on place-based projects and research. Faculty and students will often work in co-learning relationships in areas where deep expertise either does not yet exist or has been forgotten by 21st century societies. CL Universities will maintain close ties with local government/policy makers, social, political and environmental activists and entire communities, as well as a wide range of industry and non-profit partners.

The primary questions for the workshop participants to consider were: What does a day-in-the-life of a CLU student look like? What are the core disciplines? What does it mean to be local? What does it mean to be cosmopolitan?

The CL universities will have a common set of 'core' disciplines that are scaffolded by complementary disciplines representative of local/regional conditions, expertise, cultures and economy. Faculty and students will collaborate on projects, knowledge exchange, and best practices via technological interactions and physical exchanges. CL universities will provide spaces for students and faculty to participate in place-based community projects, take courses and conduct research (these form the "co-design labs" depicted at the center of Figure 3). CL students and faculty will visit traditional universities to make deeper dives into areas of knowledge or expertise that are embedded within a particular discipline or area of speciality. All CL students will take courses in two to four required 'gateway' disciplines, and design will be one of these. These courses will provide a practical and theoretical foundation for 


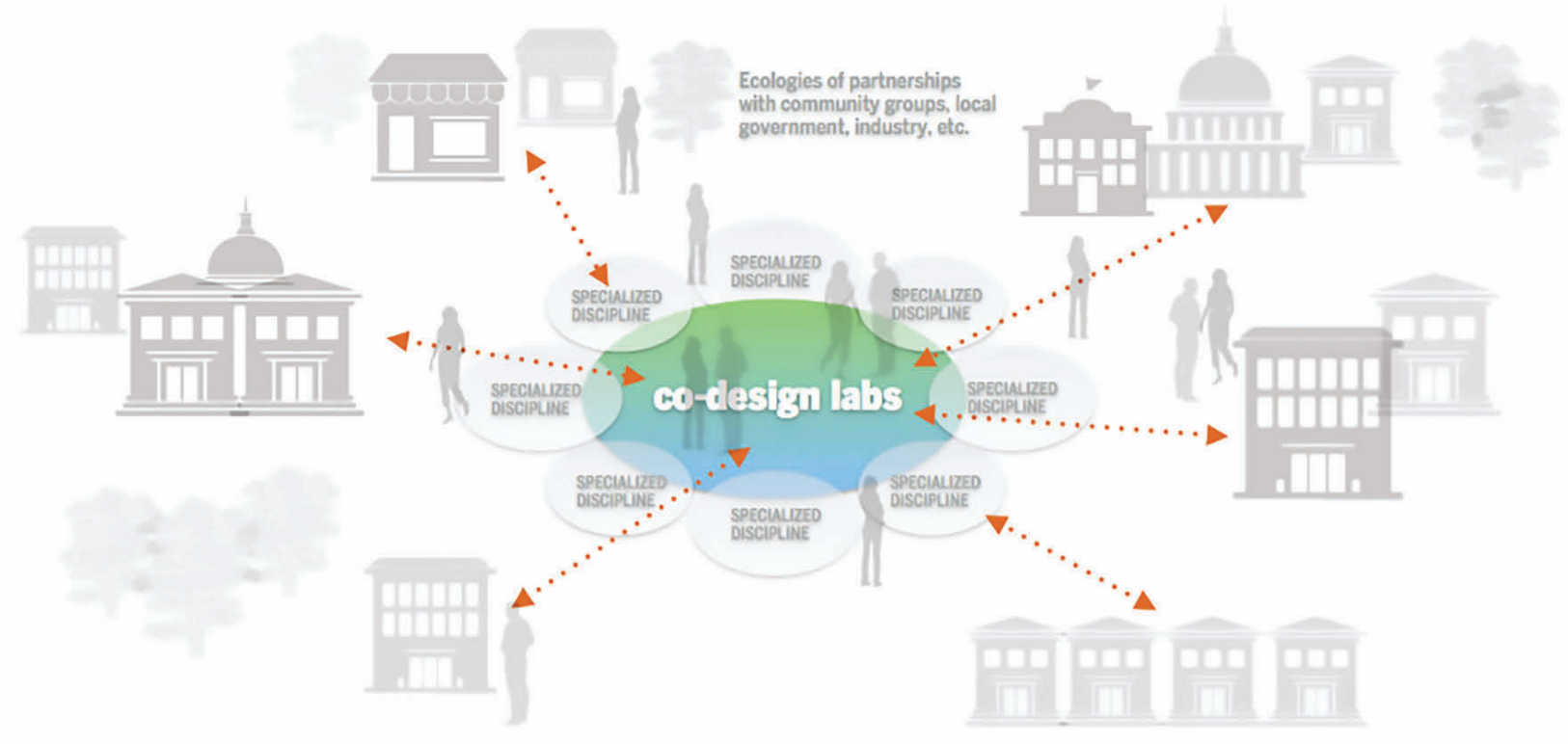

FIGURE 3: A graphical representation of the network of individuals, organizations and communities that are connected by co-design labs to Cosmopolitan Localist Universities.

place-based learning and problem-solving that emphasizes global awareness and responsibility. Students will customize degree pathways and spend about $75 \%$ of their time in transdisciplinary collaboration.

CL universities will be situated in areas where at least some indigenous flora/fauna remain so that the natural, place-based constraints and resources can inform solutions. Each CL University will be structured to help the students enrolled in it develop skills, knowledge and disciplines relevant to their particular eco-system. This is a cornerstone principle of place-based design. The University will transform into a catalyst for positive social and environmental change. Design and designers will play key roles in formulating and guiding this transformation.

\section{Scenario \#3: DesignX}

\section{Authored and presented by Pieter Jan Stappers}

The DesignX scenario ${ }^{10}$ highlights the expanding role of design and design-

\section{0}

Norman, D. \& Stappers, P. J. "DesignX: Complex Sociotechnical Systems." She Ji: The Journal of Design, Economics, and Innovation, 1.2 (2015): pgs. 83-106. ers in modern societies around the world. Over the course of the last century, the primary intent of design has broadened from being a means to invent and distribute products to being a means to develop and effectively implement interfaces, interactions, experiences, services and now complex systems, where making a change involves contributions from many parties and actors. 


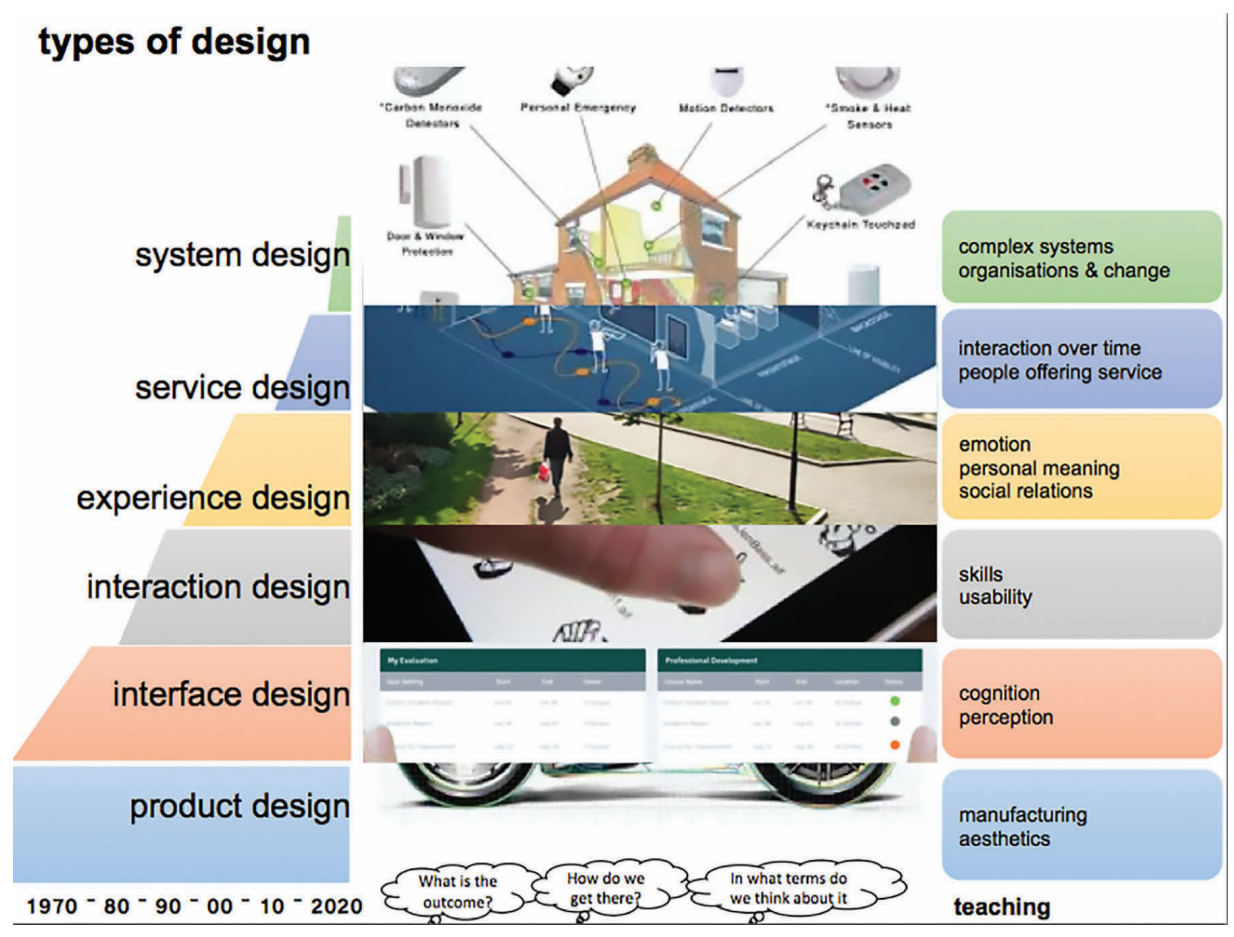

FIGURE 4: A visual representation of the progression of the types of design represented in the DesignX scenario, and what skills are taught at each level.

Examples of some of these complex systems are energy supply, healthcare services and mobility/transportation.

The change from domain-bound to purpose-driven design has led to designers' being involved in development efforts which surpass disciplines and domains. This expansion in what designers now "do" has positioned them to be involved in decision-making processes that shape public policy, affect socio-cultural and socio-economic agendas and activities, and inform thinking that impacts the functionality of civic and technological infrastructures. These newer activities of designing - identifying, framing and formulating new ways to address a wide variety of problematic situations through inventive and innovative practices - bind them together, especially when guided by a human-centered perspective. All those involved in efforts that endeavor to positively change complex systems will need to be able to operationalize design skills to varying degrees to effectively contribute to the development of these systems. These skills will include creativity, project management, communication, collaboration, empathy, prototyping and evaluation.

Partnerships will be formed around the systems of the domain of a given problematic situation, such as energy supply, healthcare services and mobility/transportation. For example, co-designing a new way to organize and 
effectively facilitate elder care across the community will require the constructive engagement of a broad cross-section of citizens, social and healthcare organizations, civil authorities, health insurance providers and designers. These collaborations are all integral to both the effective maintenance of the operation of this type of complex system as well as the exploration of new initiatives that could improve or replace it.

Cross-disciplinary development will bring together various disciplines, each with its own tools and materials, and each with its own ways of planning, doing and assessing. Models, materials, tools, and languages will need to be developed to connect and effectively manage the contributions of the different parties at the intersections, interfaces and overlaps that will occur between disciplines. The challenge in developing, implementing and effectively sustaining complex systems lies not in making a single predictable, perfect-forever solution, but in evolving solutions as they develop. This requires training that needs to take place in vivo (possibly in 'living labs'). This requires a sustained and high-level of involvement in the development of the system from various societal partners, as well as in the design activities that must occur to support that development. Each set of partners will need to be educated so that they acquire the requisite skills and understandings. By 2030, digital technologies will have matured to support large-scale information transfer, coordination of collaboration and consolidation of results. We will have developed ways to develop and prototypically test in vivo systems and services, and all involved (users, designers, managers) will be more able to easily shift between being part of running a given system to making smaller or larger changes within them. Making actual and possible changes visible to users, designers and managers, and synchronizing/harmonizing the actions of this diverse set of actors will be the main challenge.

In this scenario, the primary question posed to workshop participants was: What design skills and understandings do 'all involved' need?

\section{Scenario \#4: Distant-and-Yet-So-Close}

\section{Authored and presented by Nicole Lotz and Erik Bohemia}

The "Distant-and-Yet-So-Close" scenario proposed that a key approach for effectively facilitating distance education in design in the near-future will be to make learning relevant and "close" to an individual learner's areas of interest as well as his or her physical location, and to be structured and delivered in a manner that helps him or her develop a feeling of belonging and responsibility. 
"A "maker space" is an environment equipped with tools and people who know how to use them that operates as a center for engagement, learning, and activities that involve making and doing in a particular community.
Design students working in this scenario collaborate with a variety of stakeholders. They include, but are not limited to, learners studying in a wide variety of disciplines, as well as external stakeholders and experts from maker spaces, private companies, and public organizations such as "not-for-profits."

In this scenario, distance learners seeking to build knowledge and gain skills in design are advised and guided by a mix of artificial intelligence (AI), local expertise and online tutor groups. A 'closer to home' tutor such as a local design practitioner/teacher guides the design student throughout their learning journey. Individuals and communities of users utilize online-facilitated communications to assess and validate the outcomes of design processes, as well as design services and interactions that individual learners or groups of learners have created.

Additionally, planning and operating this scenario requires the maintenance of effective relations with the personnel who manage and operate local maker spaces, ${ }^{\text {a }}$ community mending groups and workshops. Doing this effectively is central to distance learners' exposure to hands-on designing, and the iterative, heuristically informed processes that guide it. Local companies, ranging from corporations to start-ups and local shops and small businesses, offer limited services freely or at greatly reduced rates to the distance learners, and may also offer them apprenticeships, internships or limited opportunities to practice what they have learned. Distance learners also have opportunities to contribute to the realization of local community or government projects that have been formulated to design new services and interactions.

The Distant-and-Yet-So-Close scenario is guided by a project-based curriculum that facilitates a range of projects, which include designing objects, systems and services for individuals or groups living in "the real world," as well as abstract, theoretical or philosophically motivated assignments. Cooperative and collaborative curriculum components are derived from the distance learners' online social networks and local communities. A dynamic and intelligent curriculum (AI) suggests projects to the distance learner based on social, cultural, economic or even political relevance to him or her and proximity to his or her community. As distance learners gain more experience with design processes, they gain more autonomy to choose the content that constitutes their curriculum. By being integrated within online and offline communities that operate close to the distance learner's physical location, he or she will feel more responsible, and become more socially integrated and more adept at engaging in lifelong learning. Learning to design in close proximity to an individual or 


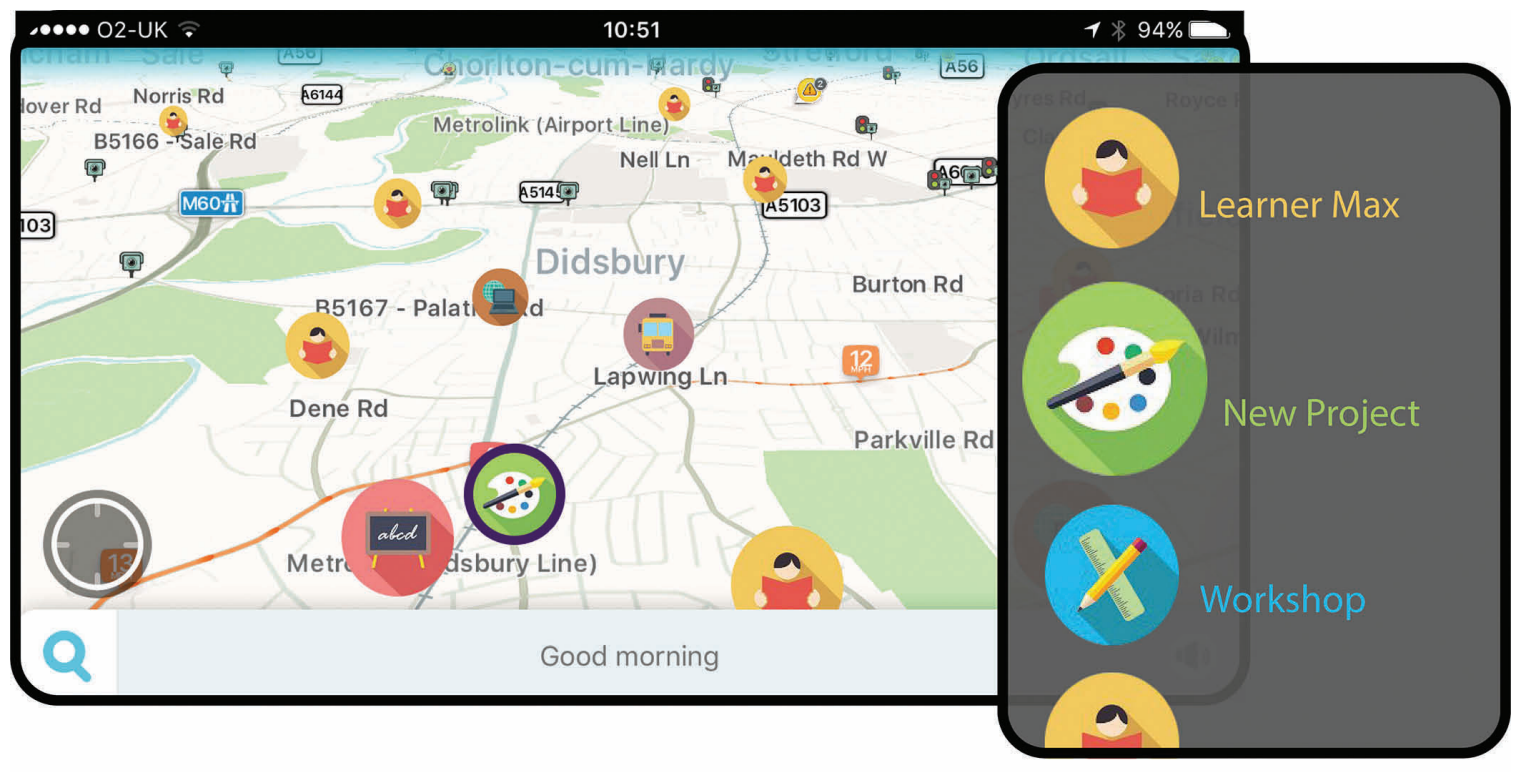

FIGURE 5: A collage of a new type of VLE - a Map-based app that depicts stakeholders, learners and workshops in physical proximity to a new project being created

group's communities of interest can promote the transformation of projects that were intended to merely satisfy a particular set of learning objectives into projects that become actualized and incorporated into the daily life of the community. Community integration and life-relevance are key to lifelong and self-directed design learning. Physical tools for prototyping and production are sourced from locally available maker spaces, local workshops, and local services (these include but are not limited to 2D and 3D printing).

The virtual tools used to facilitate design activities in this scenario are twofold: first, a central, map-based Virtual Learning Environment (VLE) (shown in Figure 5) connects learners and other stakeholders with objects, services and specific design applications that are acquired on demand. Second, distance design education will be orchestrated and facilitated virtually, but will still be anchored in physical spaces. With each new project, the VLE lists all live and past projects on a map.

The primary questions posed to workshop participants in context of this scenario were: How do we accredit ubiquitous, lifelong distance learning in the future? If the educational institutions are calling for lifelong, ubiquitous learning, then do we still need traditional accreditation? Who will accredit learning and with what goal(s)? Which elements of learning will be assessed and accredited, and how will this occur? 


\section{Future Visions for Design Education as Articulated}

\section{by Participants in the Workshops}

Workshop participants formed six groups, and each group chose one of the four scenarios to build upon their visions for the future of design education. Three groups selected the DRAW scenario, two groups selected the DesignX scenario, and one group focused on the Cosmopolitan Localist scenario as the context for their future visions. None of the groups chose to explore The Distant-andYet-So-Close scenario. For convenience, we refer to the groups in the descriptions that follow numerically as Groups 1 to 6 . The summaries of the visions for the future of design education (henceforth referred to as "visions") presented by each group are described in the following sections. These were created based upon the authors' analysis of visual and audio recordings of each group's presentation of its vision, and the authors' interpretation of the visualizations that were created to communicate these.

\section{Future visions based on the DRAW scenario}

Groups 1, 3 and 5 developed their visions based on the DRAW scenario.

Group 1 (whose visualization is depicted in Figure 6) identified that design's being added to the core of the learning experiences that constitute $\mathrm{K}-12$ education would cause greater emphasis to be placed on creative disciplines. First year students in undergraduate design will be more effectively prepared to use design knowledge and skills, while students entering disciplines outside design will be familiar with some aspects of design processes. Design learning will extend beyond classroom lecturing and the studio environment. This will result in students being able to collaborate with various constituent groups within their communities and explore the natural environment to improve less-than-desirable situations within and around them. The three wild cards (circled) - more variety, complex thinking and global interest - highlight the central ideas articulated in this visualization. Students will also need more variety regarding the types of learning experiences they are immersed in, and this will require options beyond classroom lecturing to be facilitated. Designing will involve introducing students to complex thinking, which will allow them to be braver, and to learn to experiment and take chances. Learners would need to think of design at a global scale, and learn to negotiate solutions that require collaboration, active listening and communication.

Group 3 (whose visualization is depicted in Figure 7) identified that $\mathrm{K}-12$ students who are exposed to and immersed in design-based learning 

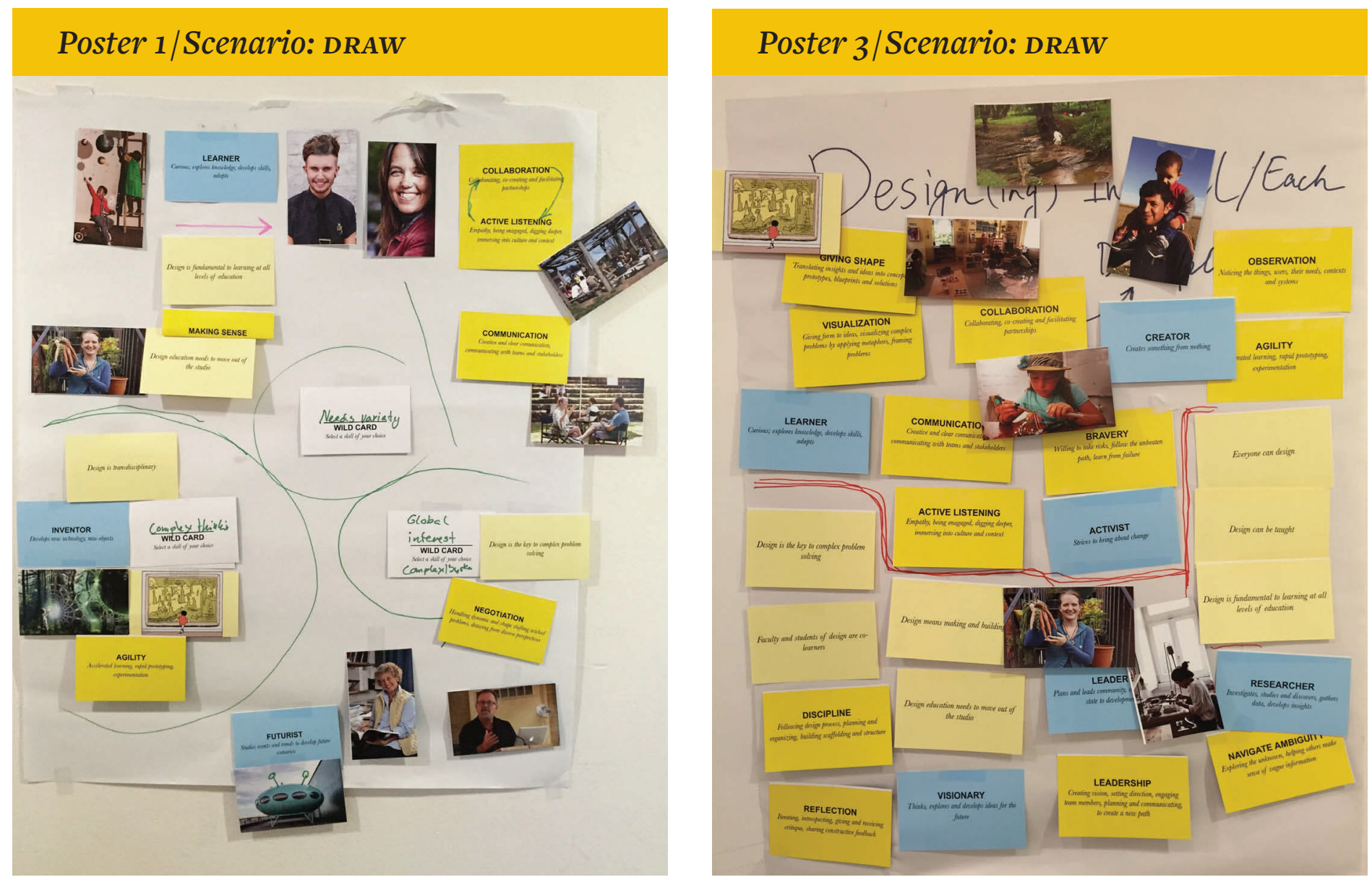

FIGURE 6 (L): Visualization for the Future of Design Education created by Group 1.

FIGURE 7 (R): Visualization for the Future of Design Education created by Group 3.

experiences will enter the university with a rich skill set in design, equipped with abilities to create, collaborate and observe with curiosity and a sense of activism. This is depicted in the visuals that occupy the upper half of the visualization. The group recognized that not everyone coming out of high school would become a professional designer. Design tools and methods will be integrated into many other disciplines. Students will pursue a Masters' degree or a $\mathrm{PhD}$ specializing in Design after earning an undergraduate degree in another discipline in addition to design. The lower half of this visualization highlights the outcomes of higher education captured through Statements Cards that characterize the transdisciplinary nature of design and Roles Cards that highlight leadership roles that students would be prepared to assume. Group 3 also contended that these students would be more well-prepared to use their experiences in higher education to become the kinds of social, civic and corporate leaders who would be able to anticipate and navigate ambiguous circumstances. Utilizing their knowledge of design skills and processes, students in every 


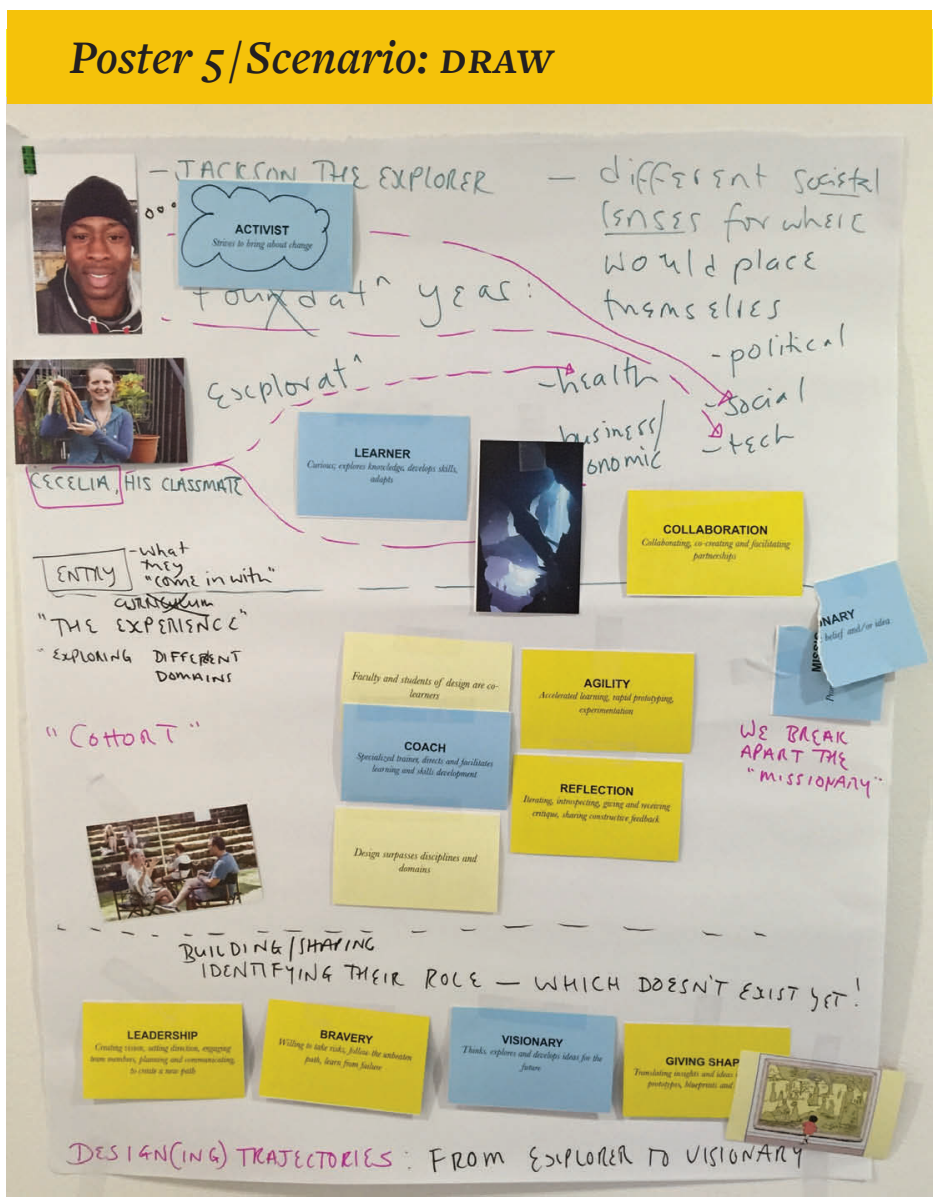

FIGURE 8: Visualization for the Future of Design Education created by Group 5.

discipline would be brave enough to identify, frame and tackle systems-level problems and/or soft and wicked problems.

Group 5 (whose visualization is depicted in Figure 8) identified that, in the DRAW scenario, $\mathrm{K}-12$ students who have been educated to plan and operate design processes would enter the university as design literates who possess diverse skills, bases of knowledge, and interests. As a result, these students' career paths would not be linear or constrained within a rigid curriculum. The design program would be designed to be an immersive learning experience. In this type of learning context, faculty and students would be co-learners who work together to create experiences within which different types of knowledge and understandings could be discovered or constructed. For example, a student possessing design skills around health and alternative economics would explore learning by using different lenses such as political, health, and business economics in the foundation phase. Being educated in this way would also allow students to explore different disciplinary domains and would encourage them to become more broad-minded explorers of society. These learning 
experiences may conclude with students actively defining and shaping their particular social and cultural roles, which may not exist yet, in a society that will require people to be more nimble learners and thinkers. Towards the end of this type of design program, students enrolled in it will begin exploring what kinds of impacts - socially, technologically, economically, politicallythey want to have on society, or some portion(s) of it, as a designers. This concept is depicted in the lower part of the visualization. The group represented the idea that "We break apart the missionary" in a torn role card. This type of design program will prepare design students to be brave leaders and visionaries who will need to be mobile, adaptable to changing situations and who can shape their own education.

\section{Visions based on the DesignX scenario}

Groups 4 and 6 developed their visions on the DesignX scenario.

Group 4 (whose visualization is depicted in Figure 9) presented the argument that, in the context of the DesignX scenario, all of the students enrolled in a design program need not learn "everything." They contended that most design students will embark on their respective learning experiences having formed their own ambitions or ideas about what they want to learn or want to become. The Role Card "learner" sits at the center of their visualization, from which radiate "arms" comprised of trigger cards depicting combinations of images and key words that together form descriptions of distinct learning personas. One of these personas describes Nina, a university student and futurist, with a horticultural background who is interested in exploring space agriculture. Since design surpasses boundaries imposed by disciplines and domains, and is structured to facilitate peer-to-peer learning, the students in the design class Nina is enrolled in will learn as much from each other as they would from their professors. This idea is highlighted by the heading for the poster that states: "We learn a lot—but not from you". In this visualization for the future, design students will learn with their Professors and Instructors - as co-learners - rather than from them.

Group 6 (whose visualization is depicted in Figure 10) focused on identifying key skills and roles required for design students to work towards. These are articulated in the "Roles" and "Skills" cards that flank each side of the column of visuals that appears in the center of their collage. The primary roles identified for future designers are explorer, futurist, visionary, inventor and 

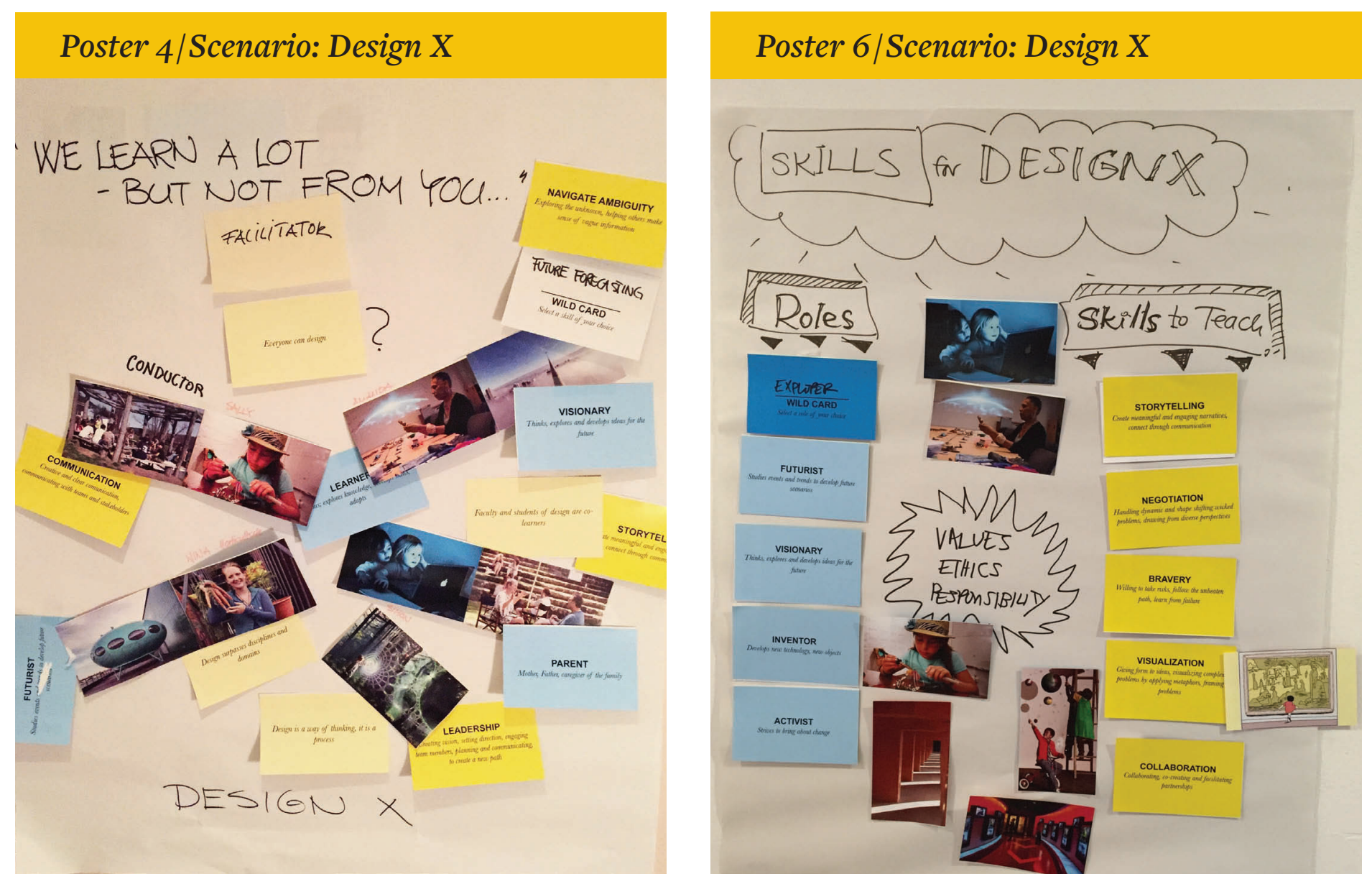

FIGURE 9 (L): Visualization for the Future of Design Education created by Group 4.

FIGURE 10 (R): Visualization for the Future of Design Education created by Group 6.

activist. The primary skills these designers would have to possess include learning by doing, storytelling, negotiation, bravery, visualization and collaboration.

The need for bravery is highly relevant to the Explorer role, which Group 6 identified on their visualization using their "Wild Card," that requires thinking in new ways. They also offered that behaving in the role of an activist means 1) actually having and then effectively articulating a point of view, and 2) considering diverse social and cultural value systems and ethical positions about topics such as intellectual property, privacy and inequality. Group 6 identified that "What makes the designers 'stand out' is their skill in storytelling...[and using this] to meaningfully engage with different types of people.” The other key ability designers learning within this vision will cultivate effectively is visualization, which was described by the group as having the skill and knowledge necessary to create something that is visually and conceptually compelling enough to provoke conversation. The group emphasized that in this future scenario the considerations of values, ethics and responsibility 


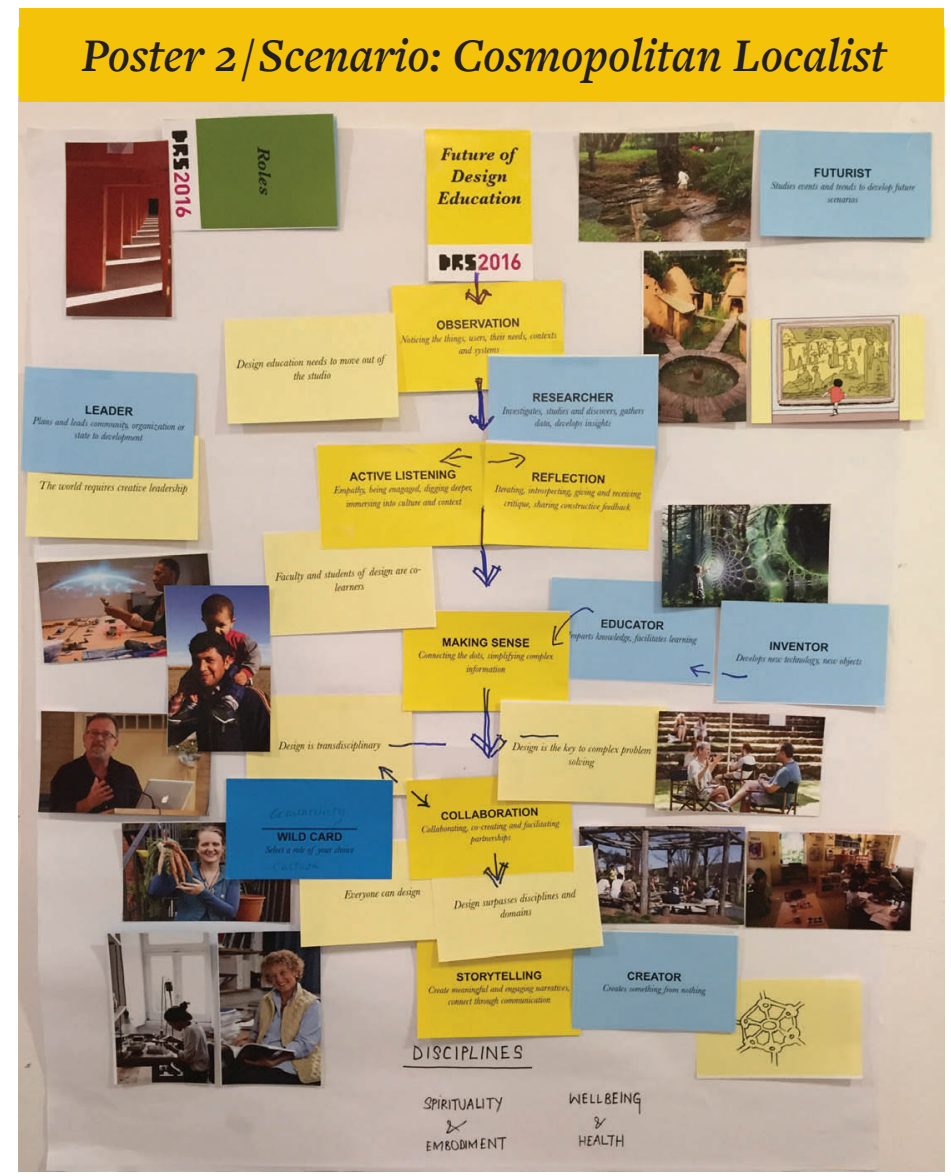

FIGURE 11: Visualization for the Future of Design Education created by Group 2.

would be central to design, placing these as text prominently in the middle of the poster. Additionally, the designers learning within this vision would need to develop skills of playfulness, experimentation and thinking at a global scale (this was not included in their visualization, but was emphasized in their verbal presentation).

Group 2 (whose visualization is depicted shown in Figure 11) developed their vision on the Cosmopolitan Localist scenario. In their vision, the future design student is on a path to discovery and respect for which environment is a core element. The learning spaces in this vision would be designed for reflection, spirituality, introspection, respect towards nature and learning to gain wisdom. Learning would not be separate from the students' other aspects of life. Family would play an important role in their everyday learning experiences. A typical day would follow the design process, which is represented along the middle spine of their visualization using the Skills Cards of observation, active listening and reflection leading to sense making, collaboration and storytelling. 
This central spine highlighting skills is supported by visuals chosen from People and Places Cards placed on either side of it. In this scenario knowledge of the local environment and indigenous materials and practices would form the core of the curriculum. Topics such as well-being, health, nourishing and flourishing of communities will be a part of learning. Faculty and students would collaborate on projects as co-learners. Designing as a key to complex problem solving would be directed towards local community problems. The students attracted to this program would have more wisdom and experience behind them and would be interested in taking up leadership roles. This community of learners would be diverse in terms of age and experience.

\section{Discussions About the Future Visions for Design Education}

The discussions around the four future scenarios that were presented during this workshop yielded distinctly different concepts and areas of foci, although there were common concepts and themes that emerged across this spectrum, such as transdisciplinarity, and collaboration between designers and non-designers.

The six visualizations created by workshop participant groups revealed a surprising amount of overlap in their choices of Roles, People, Skills, Places and Statement cards. The common themes across the six visualizations for the future of design can be observed from cards from the toolkit that were most frequently selected (these are shown in Figure 12). Collaboration was the most used Skill card and was included in five out of six of the visualizations. The importance of co-learning is highlighted by the fact that the most frequently chosen Statement card-Faculty and students of design are co-learnerswas chosen by four of the six groups. The most frequently used Role cards were Learner, Inventor and Futurist, which were included in four out of six posters. The image of a smiling woman showing off fresh produce was the most frequently chosen People card and was used by five out of six groups. The most frequently chosen Place card was an illustration showing a child attempting to enter a painting of a natural environment and was used by five out of six groups. An analysis of these most frequently chosen cards reveals that, at least in the minds of the participants in this workshop, the future of design education will be built on collaboration and co-learning. Additionally, design education in the future will not neglect study of and about how designers affect and are affected by the natural environment and will prepare design learners to act as futurists and inventors. 


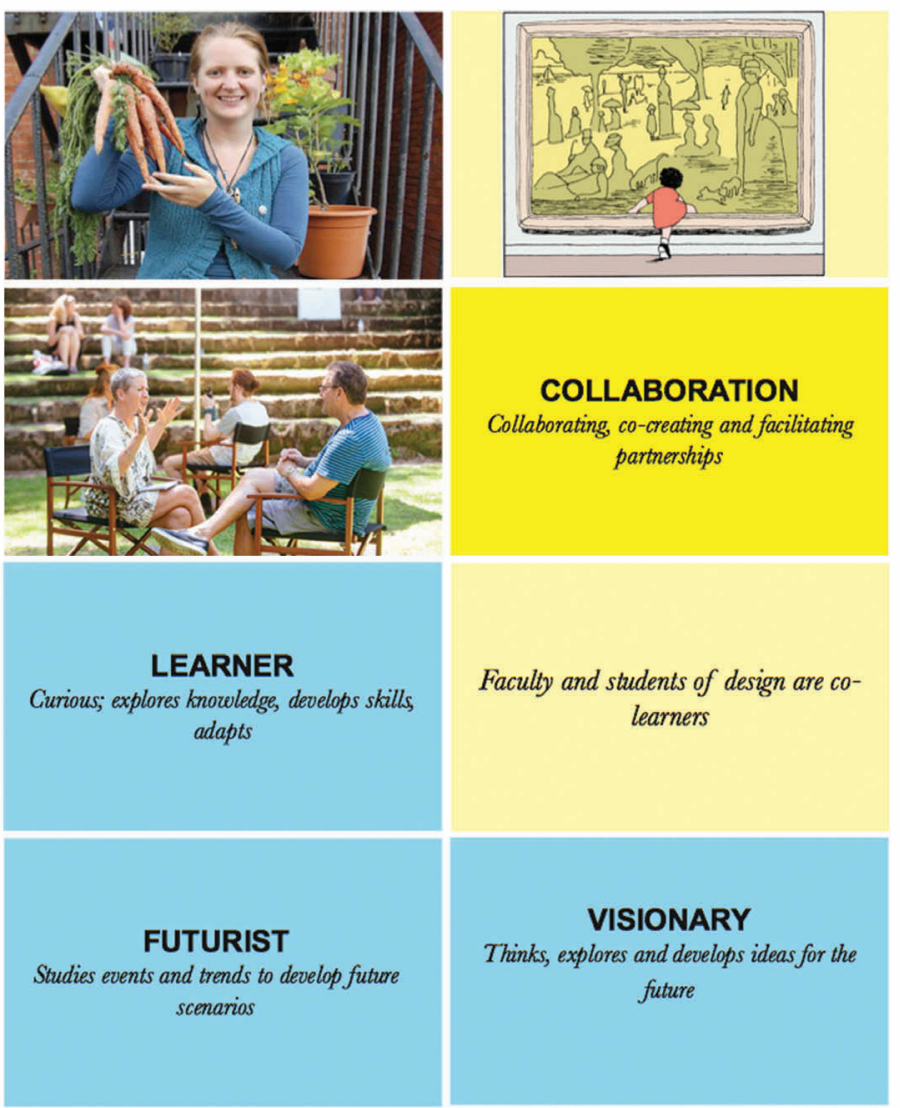

FIGURE 12: These were the most frequently selected cards from the toolkit.

Three groups highlighted that future designers would take on roles as visionaries and activists. Two groups created the Explorer role from a Wild card. Communication and storytelling were both described as important skills for future designers, as were bravery, agility, negotiation and leadership. Taken together, these indicate that future designers will have more opportunities to be proactive and to occupy positions of strength as their contributions to a broad array of social, economic and public policy initiatives evolve. The notion that design education needs to move beyond much of the current dogma that is guiding its planning and facilitation is supported by three of the six groups. These were articulated through following Statement cards: "Design education needs to move out of the studio," "Everyone can design," and "Design surpasses disciplines and domains." The visuals representing natural environments were chosen by four of the six groups indicating that future learners will move into the natural environments for an immersive learning experience. The People cards chosen by half of the groups suggest that "thinking with your hands" by manipulating 3D objects, as well as tinkering and hacking are desirable activities for future designers to engage in. 
Trigger cards that were not chosen at all were also noted. People cards that depicted men looking directly into the camera and communicating a sense of seriousness or authority were not chosen by any of the groups. These cards were passed over in favour of those that depicted women and small groups of people engaged in activities. Visuals that portrayed people moving through public spaces were also not selected. In one group's visualization, the Missionary role card was purposefully torn. The Caregiver role card was not included in any of the visualizations.

Statements (from the Statements cards) that were not chosen included: "Design can lead change," "Effective and successful design requires collaboration," "Common physical space is required for design collaboration," "Design thinking is system thinking," "Prototyping is key to effective design process," and "Design research is much more effective than scientific research." Many of these exclusions may have occurred due to redundancies and/or overlap among Roles, Skills and Statement cards. Each of the six groups seemed to prefer using a single word, such as "collaboration", instead of a statement communicating a similar concept.

Despite some large overlaps between the six visualizations, differences can be found in the details of how the Roles, Skills, People and Places acted together. For example, Group 2 emphasized the need for collaboration between different age groups. The Educator role was only mentioned in the vision presented by Group 2. Group 4 considered that the Parent role is integrated in learning and envisioned the future designer as a Conductor and Facilitator of design activities and not necessarily as the primary creator. Group 3 utilized the Skill cards Observation and Discipline. Groups 3 and 6 were the only groups to use the Skill card Visualization. As indicated that while visual communication is a key skill for many contemporary designers, it might not be as central a piece of their future skill set. Whether future designers need to adhere to an established process (e.g., as was indicated by the deployment of the Discipline card) or deviate from this (e.g., as was indicated by the deployment of the Bravery card) was and is matter of debate.

The descriptions of how traditional disciplines might play a role in the future of design education became a matter of differentiation across the six groups as well. In some of their visions, new disciplines were created in addition to design (Group 2), or design learners were described as coming to design from a disciplinary background different from design (Group 4). In yet another vision, disciplines seem to disintegrate entirely (Group 1). These approaches 
point towards interdisciplinary and transdisciplinary curricula affecting the future of design education.

Differentiation of visions was also expressed throughout the array of visual layouts created by the six groups. All of the posters displayed a different configuration and pattern of arrangement of trigger cards. These were manifest as walls of cards, or groupings of cards that were arranged in linear order or radially or configured into zones or as clusters. Cards were organized to create opposition and tensions, or bridges between concepts; arrows and lines were drawn in three of the posters to emphasize specific relationships between cards. All of this indicates that the toolkit offers enormous flexibility as a participatory framework to help disparate individuals or groups engage in processes that challenge them to envision design futures.

\section{Conclusions}

The discussions and outcomes that emerged during the visioning workshop facilitated by the authors and their colleagues during the 2016 Design Research Society Conference highlight many commonly held values and views of design educators and their future visions for design education. These have been described in terms of how they might affect those living and working within the four future scenarios for design education described in this report.

Similarities across the six visions for the future of design education emphasized the need for a collaborative approach to teaching and learning about design that entails students and faculty learning together. Each of the visions also described ways for designers to play roles as brave explorers and activists.

The variations between the six visions also gave us a sense of how and why design education may branch out in the future. The most critical variation involves how design as a discipline is placed in relation to other disciplines. On one hand, design could be absorbed into everything we do, which would mean that it would be integrated into many other disciplines. On the other hand, design as a discipline could take the lead in solving complex global problems by integrating and applying knowledge from other disciplines.

Working within the context of a future scenario offered the workshop participants a different starting point to think about the future of design education, instead of starting from today's reality, which could have been a limiting factor. The toolkit provided workshop participant groups with elements that helped to provoke their particular type of storytelling, and gave them concrete 
people, environments and skills to think and talk about. The combination of 1) challenging each of the groups to work within one of the future scenarios along with 2) providing them with a sufficiently open-ended, diversely populated and generative design toolkit helped the workshop participants create visions for the future of design education that were not overly simplistic or superficial.

This case study reveals that an approach guided by visioning enabled design educators to demonstrate in-depth and differentiated understandings about where design education could be and (perhaps should be) heading in the future. A mixture of provocative future scenarios, positive visions for select aspects of the future of design education, and descriptions of desirable futures allowed the design educators who participated in this workshop to focus on articulating the design competencies that would need to be developed to tackle and deal with our global society's uncertain futures.

\section{Acknowledgment}

We would like to thank our workshop participants and collaborators for the DRS2016 workshop: Terry Irwin, Pieter Jan Stappers and Erik Bohemia. The concept of the visioning workshop was implemented successfully due to the collective efforts and contributions of all of the facilitators and participants.

\section{References}

AIGA Educators. “2016 Design Education Programming Recap,” AIGA Design Educators Community, 10 January 2017. Online. Available at: https://educators.aiga.org/2016-design-education-conferences-recap/ (Accessed January, 19, 2017).

Broadbent, J. \& Cross, N. “Design Education in the Information Age.” Journal of Engineering Design, 14.4 (2003): pgs. 439-446.

Buchanan, R. "The Problem of Character in Design Education: Liberal Arts and Professional Specialization." International Journal of Technology and Design Education, 11.1 (2001): pgs. 13-26.

Currey, M. “D-School Futures," Core77, 6 June 2014. Online. Available at: http:// www.core77.com/posts/27564/d-school-futures-scads-owen-foster-onthe-value-of-being-a-hybrid- designer-and-the-four-most-importantqualities-in-an-id-student-27564 (Accessed January, 19, 2017).

Kressy, M., “Why MIT’s New Design Program Will Get Designers at the Table?,” 
Core 77, 9 April 2015. Online. Available at: http://www.core77.com/ posts/35588/Why-MITs-New-Design-Program-Will-Get-Designers-aSeat-at-the-Table (Accessed January, 19, 2017).

Norman, D. \& Klemmer, S., "State of Design: How Design Education Must Change.” Core77, 14 March 2014. Online. Available at: http://www. linkedin.com/pulse/20140325102438-12181762-state-of-design-how-design-education-must- change (Accessed January, 19, 2017).

Norman, D. \& Stappers, P. J. “DesignX: Complex Sociotechnical Systems.” She Ji: The Journal of Design, Economics, and Innovation, 1.2 (2015): pgs. $83-106$.

O’Neill, G. "Initiating Curriculum Revision: Exploring the Practices of Educational Developers." International Journal for Academic Development, 15.1 (2010): pgs.: 61-71.

Rodgers, P.A. \& Bremner, C. “The Concept of the Design Discipline.” D $i$ alectic, 1.1 (2016): pgs. 19-38. doi: http://dx.doi.org/10.3998/ dialectic.14932326.0001.104

Sanders, E. B.-N. and Stappers, P. J. Convivial Toolbox: Generative Research for the Front End of Design. Amsterdam, The Netherlands: BIS Publishers, 2012.

Singh, S., Irwin, T., Sanders, E., Stappers, P. J., Lotz, N., \& Bohemia, E. “The Future of Design Education.” Workshop facilitated at the Design Research Society Conference, Brighton, UK, June 2016. Online. Available at: https://drs2016.squarespace.com/564/?rq=future (Accessed January, 19, 2017).

Van der Helm, R. “The vision phenomenon: Towards a theoretical underpinning of visions of the future and the process of envisioning." Futures Methodologies, 41.2 (2009): pgs. 96-104.

Whitaker, B. “The Future of Design Education Post-Brexit," CHEAD \& APDIG, 9 September 2016. Online. Available at: http://www.policyconnect.org. uk/events/chead-apdig-“-future-design-education-post-brexit” (Accessed January, 19, 2017).

\section{Biographies}

Sapna Singh is a design researcher, strategist and educator. She is a lecturer in the Design Department at The Ohio State University in Columbus, Ohio, 
USA. As a design research consultant, she works on product development and service design for healthcare, consumer products, automobiles, retail environment, enterprise level applications and learning technology. Sapna has a multidisciplinary background with an undergraduate degree in architecture and graduate degrees in industrial design, education, business administration and design research. In 2016, Sapna completed her MFA research thesis at The Ohio State University that explored the future and value of graduate design education applying a multidisciplinary approach combining design research and organizational strategy. Her research interests are the future of design education, business strategy as a design problem and exploring design for learning.

Nicole Lotz is a Lecturer in Design at the Open University, UK. Before joining the ou, she was a Research Associate at the Hong Kong Polytechnic University and a professional Graphic/Web Designer at various design agencies in Hong Kong and Germany. She completed a Ph.D. in Cross-cultural Design at the Hong Kong Polytechnic University, and holds undergraduate and postgraduate degrees in Communication Design from Burg Giebichenstein, University of Art and Design in Halle, Germany.

Nicole is interested in design processes across the typical boundaries of domains, cultures and levels of expertise. She has studied co-located as well as distance designing across Europe, the USA, Africa and Southeast Asia. Outcomes of her research inform the development of learning designs, interactive tools and resources for co-located and distance designing and design education. Her work has affected the development of design skills and confidence in developing as well as developed countries.

Elizabeth B.-N. Sanders joined the Design Department at The Ohio State University in 2011 after working in industry as a design research consultant since 1981. She introduced many of the methods and tools being used today to drive and inspire design from a human-centered perspective and has practiced co-designing across all the design disciplines. Liz is also the founder of MakeTools, LLC where she works at the front end of many of the changes taking place today in design. Her academic research focuses on generative design research, collective creativity, and transdisciplinarity. She shares her experiences in human-centered design with clients, colleagues, and students around the world. Liz's goal is to bring participatory, human-centered design practices to the challenges we face for the future. 